\title{
Managing patients with prediabetes and type 2 diabetes after coronary events: individual tailoring needed - a cross- sectional study
}

John Munkhaugen ${ }^{1,10^{*}}$ (D, Jøran Hjelmesæth ${ }^{2,3}$, Jan Erik Otterstad ${ }^{4}$, Ragnhild Helseth ${ }^{5,6}$, Stina Therese Sollid ${ }^{7}$, Erik Gjertsen ${ }^{7}$, Lars Gullestad ${ }^{8,6}$, Joep Perk ${ }^{9}$, Torbjørn Moum ${ }^{10}$, Einar Husebye ${ }^{7}$ and Toril Dammen ${ }^{10}$

\begin{abstract}
Background: Understanding the determinants associated with prediabetes and type 2 diabetes in coronary patients may help to individualize treatment and modelling interventions. We sought to identify sociodemographic, medical and psychosocial factors associated with normal blood glucose ( $\mathrm{HbA} 1 \mathrm{c}<5.7 \%$ ), prediabetes (HbA1c 5.7-6.4\%), and type 2 diabetes.
\end{abstract}

Methods: A cross-sectional explorative study applied regression analyses to investigate the factors associated with glycaemic status and control $\left(\mathrm{HbA}_{1 c}\right.$ level) in 1083 patients with myocardial infarction and/or a coronary revascularization procedure. Data were collected from hospital records at the index event and from a self-report questionnaire and clinical examination with blood samples at 2-36 months follow-up.

Results: In all, 23\% had type 2 diabetes, 44\% had prediabetes, and 33\% had normal blood glucose at follow-up. In adjusted analyses, type 2 diabetes was associated with larger waist circumference (Odds Ratio 1.03 per $1.0 \mathrm{~cm}, p=0.001$ ), hypertension (Odds Ratio 2.7, $p<0.001$ ), lower high-density lipoprotein cholesterol (Odds Ratio 0.3 per1.0 mmol/L, $p=0$. 002) and insomnia (Odds Ratio 2.0, $p=0.002$ ). In adjusted analyses, prediabetes was associated with smoking (Odds Ratio 3.3, $p=0.001$ ), hypertension (Odds Ratio 1.5, $p=0.03$ ), and non-participation in cardiac rehabilitation (Odds Ratio 1.7, $p=0$. 003). In patients with type 2 diabetes, a higher $\mathrm{HbA}_{1 c}$ level was associated with ethnic minority background (standardized beta [ $[\beta] 0.19, p=0.005)$ and low drug adherence $(\beta 0.17, p=0.01)$. In patients with prediabetes or normal blood glucose, a higher $\mathrm{HbA}_{1 c}$ was associated with larger waist circumference $(\beta 0.13, p<0.001)$, smoking $(\beta 0.18, p<0.001)$, hypertension $(\beta 0.08, p=0.04)$, older age $(\beta 0.16, p<0.001)$, and non-participation in cardiac rehabilitation $(\beta 0.11, p=0.005)$.

Conclusions: Along with obesity and hypertension, insomnia and low drug adherence were the major modifiable factors associated with type 2 diabetes, whereas smoking and non-participation in cardiac rehabilitation were the factors associated with prediabetes. Further research on the effect of individual tailoring, addressing the reported significant predictors of failure, is needed to improve glycaemic control.

Trial registration: Retrospectively registered at ClinicalTrials.gov: NCT02309255, December 5th 2014.

Keywords: Secondary prevention, Coronary heart disease, Type 2 diabetes, Prediabetes, $\mathrm{HbA}_{1 c}$, Risk factor control, Glycaemic control, Psychosocial factors

\footnotetext{
*Correspondence: johmun@vestreviken.no

'Department of Medicine, Drammen Hospital, Vestre Viken Health Trust,

Dronninggata 41, 3004 Drammen, Norway

${ }^{10}$ Department of Behavioural Sciences in Medicine and Faculty of Medicine,

University of Oslo, Oslo, Norway

Full list of author information is available at the end of the article
}

(c) The Author(s). 2018 Open Access This article is distributed under the terms of the Creative Commons Attribution 4.0 International License (http://creativecommons.org/licenses/by/4.0/), which permits unrestricted use, distribution, and reproduction in any medium, provided you give appropriate credit to the original author(s) and the source, provide a link to the Creative Commons license, and indicate if changes were made. The Creative Commons Public Domain Dedication waiver (http://creativecommons.org/publicdomain/zero/1.0/) applies to the data made available in this article, unless otherwise stated. 


\section{Background}

The prevalence of type 2 diabetes (T2D) is rapidly increasing with the obesity epidemic [1]. Diabetes is associated with doubled long-term mortality risk after coronary heart disease (CHD) events [2] and increases the risk of both macro- (i.e. cardiovascular events) and micro- (i.e. retino-, nephro- and neuropathy) vascular complications linearly with increasing blood levels of glycated haemoglobin $\left(\mathrm{HbA}_{1 \mathrm{c}}\right)$ [3, 4]. Intensive glycaemic control by multidrug treatment regimen, as performed in randomized controlled trials, reduces the risk of micro- and macro-vascular complications in T2D patients [5], but no improvement in cardiovascular or all-cause mortality has been demonstrated.

Attempts to delay the onset of T2D and prevent or delay microvascular and macrovascular complications drew attention to prediabetes, an intermediate form of dysglycaemia between normal blood glucose and overt diabetes [6]. In the most recent US guidelines, prediabetes is defined as $\mathrm{HbA}_{1 \mathrm{c}}$ between 5.7 and 6.4\% (39-47 $\mathrm{mmol} / \mathrm{mol}$ ) [7]. Prediabetes may progress to T2D in up to $50 \%$ of cases within 5 years [8]. Also, patients with prediabetes are at increased risk of subsequent cardiovascular events after myocardial infarction [9]. Healthy lifestyle changes and treatment with antidiabetic drugs, as previously shown in clinical trials, may prevent or reduce the risk of T2D and its complications by $40-70 \%$ [10], emphasising the need for early disease detection and optimal management.

A complex array of demographic, psychosocial and behavioural factors influences T2D management [11-13], in addition to the causal risk factors increasing age, family history of diabetes, and obesity [7]. It remains to be studied carefully how these factors are associated with prediabetes and T2D, in particular within the CHD patient cohorts. The determinants of these diabetic manifestations may help to identify patients at risk, and to develop individualized interventions that may prevent prediabetes to progress to T2D and the subsequent cardiovascular events in both groups.

The NORwegian CORonary (NOR-COR) Prevention Study identifies sociodemographic, medical, and psychosocial factors associated with unfavourable risk factor control after CHD events in a cohort representing daily clinical practice (phase I). Moreover, the project aims to apply the factors of importance for risk factor control in developing tailored interventions (phase II) [14]. The present cross-sectional exploratory analysis sought to identify factors associated with glycaemic status and control among CHD patients. We hypothesise that potentially modifiable factors of importance for glycaemic status and control may be identified for those with prediabetes and T2D.

\section{Methods}

\section{Design and population}

The design, methods, and baseline patient characteristics of the NOR-COR Study have been described elsewhere
[14]. In brief, 1789 consecutive patients undergoing a first or recurrent coronary event or treatment (i.e. acute myocardial infarction, coronary artery bypass graft operation, or percutaneous coronary intervention) were identified from the hospital medical records over the 3 years (201114) prior to study inclusion. All coronary angiograms and revascularization procedures were performed by experienced invasive cardiologists and thoracic surgeons at Oslo University Hospital. Reasons for exclusion of 423 patients were cognitive impairment $(n=28)$, psychosis $(n=18)$, drug abuse $(n=10)$, short life expectancy due to end-stage organ failure, malignant disease $(n=136)$, death following discharge from index hospitalization to invitation for the follow-up visit $(n=160)$, not being able to understand Norwegian $(n=44)$, or other reasons $(n=27)$. Of the remaining 1366 eligible patients, 1127 (83\%) gave their informed consent to participate in a clinical visit and complete a comprehensive questionnaire [14]. Data on glycaemic status at follow-up were missing in 26 patients, while 18 patients with type 1 diabetes were excluded due to the different pathophysiology. Thus, a total of 1083 (96.1\%) patients were included in the present study.

The study was conducted at two Norwegian hospitals (Drammen and Vestfold Hospital Trust) with a total catchment area of 380,000 inhabitants, corresponding to approximately $7 \%$ of the Norwegian population. The catchment areas have a blend of city and rural district population representative of Norwegian geography, economy, age distribution, morbidity, and mortality [15]. The level of education in this coronary population is in line with national data on cardiovascular disease patients [15].

\section{Outcome assessment}

The primary outcome variables were glycaemic status (T2D, prediabetes or normal blood glucose) and glycaemic control $\left(\mathrm{HbA}_{1 \mathrm{c}}\right)$ at follow-up. The diagnosis of T2D was defined as either i) treatment with antidiabetic drugs or a T2D diagnosis recovered from hospital records at the time of the index event or ii) the presence of $\mathrm{HbA}_{1 \mathrm{c}} \geq 6.5 \%(\geq 48 \mathrm{mmol} / \mathrm{mol})$ at the follow-up visit. Normal blood glucose was defined by $\mathrm{HbA}_{1 \mathrm{c}}<5.7 \%$ (< $39 \mathrm{mmol} / \mathrm{mol})$, and prediabetes by $\mathrm{HbA}_{1 \mathrm{c}}$ between 5.7 and $6.4 \%(39-47 \mathrm{mmol} / \mathrm{mol})$ at follow-up, without T2D diagnosis at the index event [7]. $\mathrm{HbA}_{1 \mathrm{c}}$ was categorized based on a single blood test. Non-fasting venous whole blood sampled in an EDTA-tube was analysed on a clinical chemistry analyzer (Tosoh G8, Tosoh Medics Inc., San Francisco, CA, US) at Drammen Hospital to avoid inter-laboratory bias [14].

\section{Covariates (sociodemographic, medical, and psychosocial factors)}

Demographic and medical factors registered from hospital medical records at the time of the index event: 
- Demographic factors (age, sex, ethnic minority background defined as 1st and 2nd generation patients born in Asia, Africa or South America). Coronary history and treatment, cardiovascular medication, antidepressant medication, and somatic comorbidity summarized according to the Charlson comorbidity index.

- Participation in cardiac rehabilitation programs was confirmed by the hospital medical records and separate lists from the cardiac rehabilitation departments. In Drammen, cardiac rehabilitation includes a multidisciplinary one-day 'heart school' and exercise training twice per week for 6 weeks with start-up 2-6 weeks following the index event. Vestfold provides a comprehensive, multidisciplinary program with individual and group approaches, motivational interviewing, education and exercise described previously [14]. Start-up is 23 weeks after the index event, followed by visits twice per week for 5 weeks, with exercise duration up to 6 months.

At follow-up 2-36 months after the index event, the following study factors were provided from:

- Blood samples: Total cholesterol, low density lipoprotein (LDL) cholesterol, high density lipoprotein (HDL) cholesterol, $\mathrm{HbA}_{1 \mathrm{c}}$, and Creactive Protein (CRP).

- Clinical examination: systolic and diastolic blood pressure measured with standardized procedures using a validated digital sphygmomanometer (Welch Allyn WA Connex ProBP 3400). Weight (nearest $0.5 \mathrm{~kg}$ ), height (nearest $0.5 \mathrm{~cm}$ ), waist circumference (nearest $0.5 \mathrm{~cm}$ ).

- The self-report questionnaires $[14,16]$ :

- Socio-demographic factors: marital status and education (low education was defined by completion of primary and secondary school only).

- Medical factors: smoking, physical activity, current treatment with cardiovascular drugs, drug related side-effects and adherence (Poor drug adherence was defined by a score of $>2$ on the Morisky 8 -item medication adherence questionnaire). - Psychosocial factors: quality of life (Short-Form 12), anxiety and depression (Hospital Anxiety and Depression Scale (HADS), Type D personality (DS-14), insomnia (Bergen Insomnia Scale), illness perception (Brief illness perception questionnaire), and perceived risk perception.

The sociodemographic variables, somatic comorbidity including coronary history and treatment are descriptive factors, while the remaining medical and psychosocial factors are regarded as potentially modifiable [14]. The NOR-COR Study explores a comprehensive set of study factors in relation to the following six well-established modifiable risk factors of CHD: smoking, body mass index $\geq 30 \mathrm{~kg} / \mathrm{m}^{2}$, low or no physical activity (i.e. $<30 \mathrm{~min} \bmod$ erate activity 2-3 times/week and never or $<1$ time/week, respectively) [17], blood pressure $\geq 140 / 90$ [80 in T2D] $\mathrm{mmHg}$, LDL-cholesterol $\geq 1.8 \mathrm{mmol} / \mathrm{L}$, and unfavourable glycaemic control (i.e.T2D and prediabetes). In the present study, addressing the risk factors T2D and prediabetes as primary independent variables, the remaining five risk factors are included as co-variates as indicated.

\section{Statistical analyses}

The descriptive associations between covariates and glycaemic status are presented as frequencies (\%) and mean \pm standard deviation (SD), as appropriate. The $\chi^{2}$ test was used to compare proportions, and independent samples t-test to compare mean differences between groups. To identify the sub-set of predictors, in which all variables were statistically significant when multivariately controlled, a backwards stepwise elimination procedure was used to fit a multivariable logistic model, starting with the set of all socio-demographic, medical, and psychosocial factors with a $p$-value $<0.10$ in bivariate analyses. Odds ratios (OR) and 95\% confidence intervals (CI) for unfavourable glycaemic status by study factors were calculated. A similar backwards-stepwise elimination procedure was used to explore the linear association between $\mathrm{HbA}_{1 \mathrm{c}}$ and study factors in patients with T2D and prediabetes or neither, respectively. Beta ( $\beta$ ) coefficients (standard error) for unfavourable glycaemic control by study factors were calculated. $P$-values $<0.05$ were considered significant. Statistical interactions between study factors in ordinary least squares regressions, using HbA1c as dependent variable, were tested by entering two-way interaction terms in the equation, one at a time. Somatic co-morbidity and number of coronary events prior to the index event were not included in the regression models, as they could be direct effects rather than putative causes of T2D and unfavorable glycemic control. Statistical analyses were performed using SPSS version 21.

\section{Results}

Baseline sociodemographic, medical, and psychosocial factors differed by glycaemic status are shown in Table 1 and Table 2. ST-elevation myocardial infarction, nonST-elevation myocardial infarction and stable/unstable angina were the index coronary events in $30 \%(n=324)$, $50 \%(n=542)$ and $20 \%(n=217)$ of the patients, respectively. At the index hospitalization $16 \%(n=175)$ had a diagnosis of T2D recorded in the hospital records, whereas information about prediabetes was not available. The prevalence of T2D was $22 \%(n=243)$ at follow-up 
2-36 (median 16) months after the coronary event compatible with a further $6 \%(n=68)$ having new-onset T2D, defined by $\mathrm{HbA}_{1 \mathrm{c}} \geq 6.5 \%(\geq 46 \mathrm{mmol} / \mathrm{mol})$. Prediabetes (HbA1c 5.7-6.4\% [39-47 mmol/mol]) was present in $44 \%(n=484)$ at follow-up. Mean age at follow-up in patients with T2D and prediabetes was 62.3 (SD 9.1) years and 63.3 (SD 8.9) years, respectively, while 19\% $(n=69)$ and $22 \%(n=108)$ were women. Mean $\mathrm{HbA}_{1 \mathrm{c}}$ was $7.4 \%$ $(57 \mathrm{mmol} / \mathrm{mol}$ ) (SD 1.3) in subjects with T2D, and 55\% (n $=134$ ) did not reach the recommended treatment target of $\mathrm{HbA}_{1 \mathrm{c}}<7.0 \%(<53 \mathrm{mmol} / \mathrm{mol})$, while $35 \%(n=85)$ had $\mathrm{HbA}_{1 \mathrm{c}}>8 \%(>64 \mathrm{mmol} / \mathrm{mol})$. Antidiabetic medication was prescribed to $70 \%(n=122)$ of those with T2D at the index hospitalization, of whom $9 \%(n=15)$ used combination therapy with insulin.

Compared to patients with prediabetes, those with T2D were more frequently of ethnic minority background, had more somatic comorbidities, lower coronary risk factor control, and higher levels of CRP. They also had a higher cardiac rehabilitation participation rate, and reported insomnia more frequently. Compared to patients with normal glucose levels, those with prediabetes were significantly older, less educated, had more somatic co-morbidity, lower cardiac rehabilitation participation rate, higher prevalence of daily smoking, and more unfavourable blood pressure control.

A multi-adjusted logistic regression analysis showed the independent determinants of T2D compared to prediabetes, as well as of prediabetes compared to normal blood glucose (Table 3). Larger waist circumference, unfavourable blood pressure control, lower HDL cholesterol, insomnia, and perceived restriction in future activities due to the coronary disease were statistically significant study factors associated with T2D. The quality of life mental component was inversely related to T2D. Older age, non-participation in cardiac rehabilitation, current smoking, and unfavourable blood pressure control were statistically significantly associated with prediabetes.

A multi-adjusted linear regression analysis showed the independent determinants of $\mathrm{HbA}_{1 \mathrm{c}}$ in patients with T2D and in patients with either prediabetes or normal blood glucose level (Table 4). Ethnic minority background and low drug adherence were statistically significant study factors associated with higher $\mathrm{HbA}_{1 \mathrm{c}}$ levels in patients with T2D. Older age, higher waist circumference, current smoking, non-participation in cardiac rehabilitation and unfavourable blood pressure control were factors associated with higher $\mathrm{HbA}_{1 \mathrm{c}}$ in patients with prediabetes or normal blood glucose. The positive gradient between HbA1c and age was significantly stronger among those with prediabetes or normal blood glucose compared to those with T2D (F 32.4, $p<0.001$ ). A corresponding stronger association between $\mathrm{HbA} 1 \mathrm{c}$ and non-participation in cardiac rehabilitation (F 18.2, $p<$ 0.001 ) and unfavourable blood pressure control (F 7.6, $p$ $=0.006$ ) was found. The positive association between HbA1c and ethnic minority background (F 17.2, $p<$ 0.001) and low drug adherence (F 29.2, $p<0.001$ ) was significantly stronger among those with T2D compared to those with prediabetes or optimal blood sugar.

\section{Discussion}

In this cohort representing routine clinical practice, 2 of 3 patients had either prediabetes or T2D 2-36 months after hospitalization for a coronary event. The novelty of the present study is the detailed analysis of sociodemographic, medical and psychosocial factors providing new knowledge that potentially may improve risk factor control in the CHD population with disturbed glucose metabolism. The stratification of CHD patients into T2D, prediabetes and normal glucose control has been reported only once previously, in a US population without cardiovascular disease [18], and thus contributes to the originality of the present findings. Differences in the strength of associations of the potentially modifiable factors across the levels of glycemic status are demonstrated in the present study. For example, non-participation in cardiac rehabilitation emerges as a particular challenge in patients with prediabetes, while insomnia seems to be of particular importance for patients with T2D. The small sub-group of patients with ethnic minority background deserves particular attention due to their high risk of T2D and poor glycaemic control, as previously reported [19]. Patients with prediabetes at a cardiac event emerge as a particularly relevant subgroup to address more carefully in future secondary prevention of CHD.

The coronary index events in the present study are a ST-elevation myocardial infarction [20], and angina/ non-ST-elevation myocardial infarction diagnoses [21]. Differences in pathophysiology, presentation and acute and long-term management of prediabetes and T2D could potentially influence our study results [20, 21]. Even though the relative number of patients with prediabetes and T2D varied by the coronary index diagnosis, the type of index event was not associated with glycemic status or control in adjusted analyses. An elegant randomised controlled study by Marfella $\mathrm{R}$ et al. demonstrated that optimal peri-procedural glycemic control up-regulated endothelial progenitor cell level and differentiation during acute ST-elevation myocardial infarction, with the results supporting the notion that tight glycemic control may improve myocardial salvage [22]. In our study, however, glycaemic status was assessed 2-36 months after the coronary event, and whether these mechanisms may explain any potential beneficial effect of tight glycemic control several months after the acute event is unknown. 
Table 1 Sociodemographic and medical factors in coronary patients with normal blood glucose, prediabetes and type 2 diabetes

\begin{tabular}{|c|c|c|c|c|c|}
\hline & $\begin{array}{l}\text { Normal blood } \\
\text { glucose }\end{array}$ & Prediabetes & $\begin{array}{l}\text { Type } 2 \\
\text { diabetes }\end{array}$ & $P$-Value & \\
\hline & $(n=356,32.4 \%)$ & $\begin{array}{l}(n=484 \\
44.1 \%)\end{array}$ & $\begin{array}{l}(n=243 \\
22.4 \%)\end{array}$ & $\begin{array}{l}\text { Normal blood glucose vs. } \\
\text { prediabetes }\end{array}$ & $\begin{array}{l}\text { Type } 2 \text { diabetes vs. } \\
\text { prediabetes }\end{array}$ \\
\hline \multicolumn{6}{|l|}{ Socio-demographic factors } \\
\hline Age in years at index event, mean (SD) & $59.4(9.9)$ & $63.3(8.9)$ & $62.3(9.1)$ & $* * *$ & N.S. \\
\hline $\begin{array}{l}\text { Number of months from index event to follow-up, } \\
\text { mean (SD) }\end{array}$ & $16.2(10.3)$ & $17.0(10.5)$ & $18.3(10.5)$ & N.S. & N.S. \\
\hline Female sex, n (\%) & $69(19.4)$ & $108(22.3)$ & $49(20.2)$ & N.S. & N.S. \\
\hline Ethnic minority, $\mathrm{n}(\%)^{\mathrm{a}}$ & $5(1.4)$ & $10(2.1)$ & $18(7.4)$ & N.S. & $* * *$ \\
\hline Living alone, n (\%) & $57(16.0)$ & $84(17.4)$ & $50(21.7)$ & N.S. & N.S. \\
\hline Low education, $\mathrm{n}(\%)^{\mathrm{b}}$ & $221(62.1)$ & $346(71.5)$ & $181(76.1)$ & $* *$ & N.S. \\
\hline \multicolumn{6}{|l|}{ Medical factors } \\
\hline \multicolumn{6}{|l|}{ Coronary index diagnosis, n (\%) } \\
\hline Non-ST elevation myocardial infarction & $170(47.8)$ & $247(51.0)$ & $123(40.1)$ & N.S. & * \\
\hline ST-elevation myocardial infarction & $111(31.1)$ & $148(30.6)$ & $58(23.9)$ & N.S. & N.S. \\
\hline Stable or unstable angina & $75(21.1)$ & $89(18.4)$ & $62(25.5)$ & N.S. & N.S. \\
\hline$>1$ coronary event prior to the index event, $\mathrm{n}(\%)$ & $91(25.6)$ & $119(24.6)$ & $113(46.5)$ & N.S. & $* * *$ \\
\hline Participation in cardiac rehabilitation, n (\%) & $183(51.4)$ & $206(42.6)$ & $139(57.2)$ & * & $* * *$ \\
\hline Charlson co-morbidity score, mean (SD) & $3.6(1.4)$ & $4.1(1.3)$ & $4.8(1.5)$ & $* * *$ & $* * *$ \\
\hline Chronic kidney disease (eGFR <60), n (\%) & $30(8.4)$ & $58(12.0)$ & $45(20.3)$ & N.S. & * \\
\hline $\begin{array}{l}\text { Antidepressant medication at the time of the index } \\
\text { event, } n(\%)\end{array}$ & $16(4.5)$ & $16(3.3)$ & $21(8.6)$ & N.S. & ** \\
\hline \multicolumn{6}{|l|}{ Coronary risk factors and medication at interview } \\
\hline $\begin{array}{l}\text { Low density lipoprotein cholesterol mmol/L, } \\
\text { mean (SD) }\end{array}$ & $2.15(0.73)$ & $2.09(0.80)$ & $2.07(0.84)$ & N.S. & N.S. \\
\hline $\begin{array}{l}\text { Low density lipoprotein cholesterol } \geq 1.8 \mathrm{mmol} / \mathrm{L} \text {, } \\
\mathrm{n}(\%)\end{array}$ & $222(62.4)$ & $273(56.4)$ & $122(51.0)$ & N.S. & N.S. \\
\hline $\begin{array}{l}\text { High density lipoprotein cholesterol mmol/L, } \\
\text { mean (SD) }\end{array}$ & $1.19(0.34)$ & $1.16(0.32)$ & $1.02(0.30)$ & N.S. & $* * *$ \\
\hline Current smoking, n (\%) & 49 (13.8) & $115(23.8)$ & $53(22.7)$ & $* * *$ & N.S. \\
\hline C-reactive protein in $\mathrm{mg} / \mathrm{L}$, mean (SD) & $2.06(2.13)$ & $2.37(2.73)$ & $3.22(2.89)$ & N.S. & $* * *$ \\
\hline C-reactive protein $\geq 2$ mg/L, n (\%) & $123(35.5)$ & $172(36.6)$ & $131(56.5)$ & N.S. & $* * *$ \\
\hline $\begin{array}{l}\text { Physical activity }<30 \text { min of moderate activity } 2- \\
3 \text { times a week, } n(\%)\end{array}$ & $158(44.5)$ & $227(48.4)$ & $129(54.2)$ & N.S. & N.S. \\
\hline Physical activity < 1 time a week, n (\%) & $53(14.9)$ & $73(15.1)$ & $59(24.9)$ & N.S. & $* *$ \\
\hline $\begin{array}{l}\text { Blood pressure } \geq 140 / 90 \text { ( } 80 \text { in diabetes) } \mathrm{mmHg} \text {, } \\
\text { n (\%) }\end{array}$ & $118(33.1)$ & $198(44.0)$ & $129(60.6)$ & $* * *$ & $* * *$ \\
\hline Waist circumference, mean (SD) & $100.1(11.1)$ & $101.3(12.1)$ & $108.5(12.6)$ & N.S. & $* * *$ \\
\hline $\begin{array}{l}\text { Waist circumference } \geq 102 / 88 \mathrm{~cm} \text { in men/ } \\
\text { women, } \mathrm{n}(\%)\end{array}$ & $168(51.5)$ & $258(57.5)$ & $164(76.6)$ & N.S. & $* * *$ \\
\hline Body Mass Index $\geq 30$ kg/m², n (\%) & $84(23.6)$ & $133(27.5)$ & $116(54.2)$ & N.S. & $* * *$ \\
\hline Fruit and vegetables $<2$ units/day, n (\%) & $132(37.6)$ & $187(38.6)$ & $92(39.7)$ & N.S. & N.S. \\
\hline Fish meals < 3 times/week, n (\%) & $171(48.0)$ & $213(44.0)$ & $118(48.6)$ & N.S. & N.S. \\
\hline \multicolumn{6}{|l|}{ Medication at interview, n (\%) } \\
\hline Statin, n (\%) & $332(93.3)$ & $451(93.2)$ & $224(92.2)$ & N.S. & N.S. \\
\hline High-intensity statin therapy, n (\%) & $168(47.2)$ & $247(51.0)$ & $104(55.9)$ & N.S. & N.S. \\
\hline Aspirin, n (\%) & $351(98.6)$ & $467(96.5)$ & $235(96.7)$ & N.S. & N.S. \\
\hline Beta-blockers, n (\%) & $248(69.7)$ & $349(72.1)$ & $188(77.4)$ & N.S. & N.S. \\
\hline
\end{tabular}


Table 1 Sociodemographic and medical factors in coronary patients with normal blood glucose, prediabetes and type 2 diabetes (Continued)

\begin{tabular}{clllll}
\hline & $\begin{array}{l}\text { Normal blood } \\
\text { glucose }\end{array}$ & Prediabetes & Type 2 \\
diabetes & & P-Value \\
& $(n=356,32.4 \%)$ & $(n=484$, & $\begin{array}{l}(n=243, \\
44.1 \%)\end{array}$ & $\begin{array}{l}\text { Normal blood glucose vs. } \\
\text { prediabetes }\end{array}$ & $\begin{array}{l}\text { Type } 2 \text { diabetes vs. } \\
\text { prediabetes }\end{array}$ \\
\hline ACE-inhibitors or ARB, $\mathrm{n}(\%)$ & $166(46.6)$ & $232(47.9)$ & $143(58.8)$ & N.S. & $* *$ \\
Low Morisky Scorec, $\mathrm{n}(\%)$ & $38(10.7)$ & $40(8.3)$ & $22(9.6)$ & N.S. & N.S. \\
\hline
\end{tabular}

$S D$ standard deviation, NS not significant, eGFR estimated glomerular filtration rate, $A C E$ angiotensin converting enzyme, $A R B$ angiotensin receptor blocker. ${ }^{*} p<$ $0.05,{ }^{* *} p<0.01,{ }^{* * *} p<0.001$

${ }^{a}$ Ethnic minority was defined as 1st and 2nd generation patients born in Asia, Africa and South America

bow education was defined as completion of primary and secondary school only

'Scores: > 2 on the Morisky 8-item medication adherence questionnaire, indicating low adherence

Table 2 Psychosocial factors, quality of life, illness and risk factor perception in coronary patients with normal blood glucose, prediabetes and type 2 diabetes

\begin{tabular}{|c|c|c|c|c|c|}
\hline \multirow[t]{2}{*}{ Study factors } & \multirow{2}{*}{$\begin{array}{l}\text { Normal } \\
\text { blood } \\
\text { glucose } \\
(n=356 \\
32.4 \%)\end{array}$} & \multirow{2}{*}{$\begin{array}{l}\text { Prediabetes } \\
(n= \\
484,44.1)\end{array}$} & \multirow{2}{*}{$\begin{array}{l}\text { Type } 2 \\
\text { diabetes } \\
(n=243 \\
22.4 \%)\end{array}$} & \multicolumn{2}{|l|}{$P$-Value } \\
\hline & & & & $\begin{array}{l}\text { Prediabetes vs. } \\
\text { normal blood } \\
\text { glucose }\end{array}$ & $\begin{array}{l}\text { Type } 2 \text { diabetes } \\
\text { vs. prediabetes }\end{array}$ \\
\hline \multicolumn{6}{|l|}{ Psychosocial factors and quality of life } \\
\hline Hospital Anxiety and Depression Score-Anxiety $\geq 8, n$ (\%) & $66(19.2)$ & $99(21.5)$ & $53(22.9)$ & NS & NS \\
\hline Hospital Anxiety and Depression Score-Depression $\geq 8, n$ (\%) & $49(14.0)$ & $62(13.3)$ & $40(17.2)$ & NS & NS \\
\hline Type D personality disorder, n (\%) & $62(17.4)$ & $82(16.9)$ & $44(18.7)$ & NS & NS \\
\hline Worry score (Penn State Worry Questionnaire), mean (SD) & $37.8(12.4)$ & $38.0(13.0)$ & $\begin{array}{l}38.9 \\
(12.5)\end{array}$ & NS & NS \\
\hline Insomnia, n (\%) & $157(44.1)$ & $186(38.4)$ & $\begin{array}{l}124 \\
(54.1)\end{array}$ & NS & $* * *$ \\
\hline Quality of life (SF-12), physical component summary, mean (SD) & $39.0(4.7)$ & $38.3(4.6)$ & $37.9(5.1)$ & * & NS \\
\hline Quality of life (SF-12), mental component summary, mean (SD) & $45.9(6.1)$ & $46.5(6.4)$ & $45.0(6.8)$ & NS & ** \\
\hline \multicolumn{6}{|l|}{ Illness and risk factor perception (1-10 Likert scale), mean (SD) } \\
\hline $\begin{array}{l}\text { What do you feel is the likelihood of having a new heart attack } \\
\text { over the next } 12 \text { months? }\end{array}$ & $2.5(2.3)$ & $2.7(2.4)$ & $3.1(2.6)$ & NS & NS \\
\hline $\begin{array}{l}\text { How much do you feel you can help reduce your risk of having } \\
\text { another heart attack? }\end{array}$ & $6.4(2.7)$ & $6.6(2.8)$ & $6.1(2.8)$ & NS & * \\
\hline $\begin{array}{l}\text { How much do you think you will have to restrict your activities } \\
\text { in the long-term due to your heart condition? }\end{array}$ & $3.0(2.7)$ & $3.3(2.7)$ & $4.1(2.9)$ & NS & $* * *$ \\
\hline \multicolumn{6}{|l|}{ Brief IIIness Perception (1-10 Likert scale), mean (SD) } \\
\hline How much does your illness affect your life? (consequences) & $3.6(2.8)$ & $3.6(2.8)$ & $4.3(2.9)$ & NS & ** \\
\hline How long do you think your illness will continue? (timeline) & $7.7(3.3)$ & $7.6(3.3)$ & $7.9(3.0)$ & NS & NS \\
\hline $\begin{array}{l}\text { How much control do you feel you have over your illness? } \\
\text { (personal control) }\end{array}$ & $5.9(2.8)$ & $5.9(2.9)$ & $5.9(2.7)$ & NS & NS \\
\hline $\begin{array}{l}\text { How much do you think your treatment can help you? } \\
\text { (treatment control) }\end{array}$ & $7.3(2.3)$ & $7.4(2.4)$ & $7.2(2.4)$ & NS & NS \\
\hline $\begin{array}{l}\text { How much do you experience symptoms from your illness? } \\
\text { (identity) }\end{array}$ & $3.0(2.5)$ & $3.0(2.7)$ & $4.0(2.9)$ & NS & $* * *$ \\
\hline How concerned are you about your illness? (concern) & $3.5(2.8)$ & $3.6(3.0)$ & $4.0(3.1)$ & NS & NS \\
\hline $\begin{array}{l}\text { How well do you feel you understand your illness? } \\
\text { (understanding) }\end{array}$ & $6.9(2.6)$ & $7.0(2.6)$ & $6.7(2.5)$ & NS & NS \\
\hline $\begin{array}{l}\text { How much does your illness affect you emotionally? (emotional } \\
\text { response) }\end{array}$ & $3.4(3.0)$ & $3.4(3.0)$ & $4.0(3.0)$ & NS & * \\
\hline
\end{tabular}


Table 3 Multivariable ${ }^{a}$ odds ratios (confidence intervals and $p$-values) for prediabetes and type 2 diabetes by study factors

\begin{tabular}{|c|c|c|c|c|}
\hline \multirow[t]{2}{*}{ Study factors } & \multicolumn{2}{|c|}{$\begin{array}{l}\text { Prediabetes (1) vs. } \\
\text { normal blood glucose } \\
\text { (0) }\end{array}$} & \multicolumn{2}{|c|}{$\begin{array}{l}\text { Type } 2 \text { diabetes } \\
\text { (1) vs. prediabetes } \\
\text { (0) }\end{array}$} \\
\hline & Odds ratio $(95 \%$ & Cl) & $\begin{array}{l}\text { Odds ratio ( } \\
\text { Cl) }\end{array}$ & $95 \%$ \\
\hline Age at index event per 1.0 year & $1.05(1.03-1.07)$ & $\begin{array}{l}< \\
0.001\end{array}$ & & NS \\
\hline Waist circumference per $1.0 \mathrm{~cm}$ & & NS & $\begin{array}{l}1.03(1.01- \\
1.05)\end{array}$ & 0.001 \\
\hline Non-participation in cardiac rehabilitation & $1.69(1.19-2.40)$ & 0.003 & & NS \\
\hline Current smoking & $3.29(2.00-5.42)$ & 0.001 & & NS \\
\hline Blood pressure $\geq 140 / 90$ ( 80 in diabetes) $\mathrm{mmHg}$ & $1.48(1.04-2.11)$ & 0.030 & $\begin{array}{l}2.67(1.74- \\
4.11)\end{array}$ & 0.001 \\
\hline Quality of life (SF-12), mental component per 1.0 points & & NS & $\begin{array}{l}0.97(0.94- \\
0.99)\end{array}$ & 0.042 \\
\hline Insomniab & & NS & $\begin{array}{l}1.98(1.30- \\
3.05)\end{array}$ & 0.002 \\
\hline $\begin{array}{l}\text { How much do you think you will have to restrict your activity in the long term due to your heart } \\
\text { condition? per } 1.0 \text { points }{ }^{c}\end{array}$ & & NS & $\begin{array}{l}1.14(1.06- \\
1.23)\end{array}$ & 0.001 \\
\hline
\end{tabular}

SD standard deviation, NS: not significant, $\mathrm{Cl}$ confidence interval

${ }^{a}$ Multi-adjusted models using backward step-wise elimination in binary logistic regression analyses adjusted for study and starting with risk factors showing $p<0.1$ in bivariate association

bInsomnia (Bergen insomnia scale): a 7 -item self-report inventory designed to assess primary insomnia

'Measured by the Perceived risk perception Questionnaire (1-10 Likert scale)

Although long-term mortality after coronary events has declined in line with improved acute treatment and better risk factor management, patients with $\mathrm{T} 2 \mathrm{D}$ are at particular risk for recurrent cardiovascular events [23]. Similarly, a meta-analysis has also demonstrated that compared to subjects with normal glycaemic status, those with prediabetes experienced a $20 \%$ increased risk for cardiovascular disease [9]. The mechanisms behind the poor prognosis in patients with T2D and prediabetes are not completely understood, but a higher prevalence of complications in combination with lack of appropriate secondary preventive treatment contribute [24]. It was therefore not unexpected that patients with T2D had most somatic comorbidty and poorest overall risk factor control, followed by subjects with prediabetes. Subjects with normal blood glucose had least comorbidity and best coronary risk profile. Interestingly, T2D patients were characterized by central obesity, unfavourable blood pressure, and low levels of HDL cholesterol, which constitute important components of the metabolic syndrome [25].

The T2D patients in our study were characterized by subclinical inflammation. The association between high-sensitivity CRP and T2D, however, was no longer significant when adjusting for somatic comorbidity and other cardiovascular risk factors in our study. Inflammation, particularly in diabetes, plays a pivotal role in the series of events that result in plaque disruption and thus influence the incidence and severity of cardiovascular events in T2D patients [26]. The involvement of the gene regulating transcription factor sirtuin 6 in the inflammatory

Table $4 \mathrm{HbA} 1 \mathrm{c}$ regressed on study factors by multi-adjusted ${ }^{a}$ linear regression analysis

\begin{tabular}{|c|c|c|c|c|c|c|}
\hline \multirow{3}{*}{$\begin{array}{l}\text { Study factors } \\
\text { Age at index event per year }\end{array}$} & \multicolumn{3}{|c|}{ Prediabetes or normal blood glucose $(n=840)$} & \multicolumn{3}{|c|}{ Type 2 diabetes $(n=243)$} \\
\hline & \multirow{2}{*}{$\frac{b \text { (standard error) }}{0.006(0.001)}$} & \multicolumn{2}{|l|}{ Standardized $\beta$} & \multirow[t]{2}{*}{ b (standard error) } & \multicolumn{2}{|l|}{ Standardized $\beta$} \\
\hline & & 0.157 & $p<0.001$ & & & \\
\hline Ethnic minority background & & & NS & $1.06(0.370)$ & 0.193 & $p=0.005$ \\
\hline Non-participation in cardiac rehabilitation & $0.074(0.027)$ & 0.106 & $p=0.005$ & & & NS \\
\hline Waist circumference per $1.0 \mathrm{~cm}$ & $0.003(0.001)$ & 0.131 & $p<0.001$ & & & NS \\
\hline Current smoking & $0.157(0.033)$ & 0.177 & $p<0.001$ & & & NS \\
\hline Blood pressure $\geq 140 / 90$ ( 80 in diabetes) $\mathrm{mmHg}$ & $0.056(0.027)$ & 0.079 & $p=0.037$ & & & NS \\
\hline Low self-report drug adherence ${ }^{b}$ & & & NS & $0.668(0.265)$ & 0.168 & $p=0.012$ \\
\hline
\end{tabular}

NS not significant

Unstandardized (b) and standardized $(\beta)$ regression coefficients. ${ }^{a}$ Adjusted for all variables with $p \leq 0.10$ retained in backward elimination linear regression analysis

${ }^{b}$ Scores: $>2$ on the Morisky 8-item medication adherence questionnaire indicating low adherence 
diabetic atherosclerotic lesions was recently established. Incretin-based therapies (i.e. GLP-1 receptor agonists, and dipeptidyl peptidase-4 inhibitors) resulted in a greater sirtuin 6 expression and less inflammation and oxidative stress in carotid plaques of diabetic versus non-diabetic patients, indicating a more stable plaque phenotype [27]. The prevalence and predictors of culprit coronary plaque rupture identified by optical coherence tomography in patients undergoing coronary angiography was recently described in a meta-analysis by Iannaccone et al. which showed high rates of plaque rupture in patients with acute coronary syndrome [28]. Hypertension was the only clinical predictor for ST-elevation myocardial infarction, whereas increasing age, diabetes and hyperlipidemia were clinical predictors in non- ST-elevation myocardial infarction and unstable angina [28]. Another interesting endocrinological aspect of inflammation is the association with subclinical hypothyroidism independent of the traditional risk factors, as demonstrated by Marfella et al. [29]. Their study showed a potential interplay between subclinical hypothyroidism and inflammatory activity in atherosclerotic plaque progression towards instability, and that synthetic levothyroxine replacement therapy might contribute to plaque stabilization and thus improved prognosis by inhibiting the immunitydependent plaque rupture in patients with subclinical hypothyroidism [29].

Low self-reported drug adherence was significantly associated with higher $\mathrm{HbA}_{1 \mathrm{c}}$ level in T2D, but not in prediabetic patients. Among patients with T2D having $\mathrm{HbA}_{1 \mathrm{c}}>$ $8.0 \%$ (64 mmol $/ \mathrm{mol}), 30 \%$ did not use antidiabetic drugs, while only $9 \%$ used combination therapy with antidiabetic drugs and insulin. Intensified antidiabetic treatment and strategies to improve drug adherence therefore appear to be the major factors needed to improve glycaemic control in T2D patients. The newer hypoglycemic drugs, in particular incretins, are recommended for T2D patients with established CHD [6], and their potential beneficial pleiotropic effects on atherosclerotic plaque functionality and thus clinical outcome was recently documented in patients with a non-obstructive coronary artery stenosis non-ST-elevation myocardial infarction event [30].

In a long-term follow-up of patients with T2D and microalbuminuria without CHD participating in the Steno-2 trial, Gæde et al. showed that intensive target-driven intervention with multiple drug combinations and behaviour modification had sustained beneficial effects on the incidence of cardiovascular events and mortality compared to conventional multifactorial treatment [31]. The intensive drug regimen included higher dosages of statins and ACEinhibitors than that of conventional treatment, resulting in lower LDL cholesterol and systolic blood pressure. These findings emphasize the importance of adequate prescription of and adherence to secondary preventive drug therapy in T2D patients.
The risk factors obesity, smoking and unfavorable blood pressure control were also significantly associated with increasing $\mathrm{HbA}_{1 \mathrm{c}}$ level in the group of patients with prediabetes or normal blood glucose, but not in those with T2D. The pharmacological treatment of T2D, aiming at $\mathrm{HbA}_{1 \mathrm{c}}$ control, may partly account for these differences at group level. The present finding thus emphasizes the particular need to address glycemic control through appropriate lifestyle changes and drug treatement, even in CHD patients without T2D [10].

Participation in multidisciplinary cardiac rehabilitation programme is strongly recommended and has proven beneficial for several cardiovascular risk factors in CHD patients with and without diabetes [32]. Participation in a comprehensive cardiac rehabilitation program was associated with improved risk profile as well as drug adherence in a recent publication derived from our data set [33]. In the present study, the participation rate in cardiac rehabilitation was lowest in patients with prediabetes, and was significantly related to increasing $\mathrm{HbA}_{1 \mathrm{c}}$ level. Even though patients with $\mathrm{T} 2 \mathrm{D}$ had the highest participation rate in cardiac rehabilitation, more than $40 \%$ did not participate. Efforts to increase the participation rate in effective preventive cardiac rehabilitation programs are of particular importance for both patients with prediabetes and T2D, as non-participation appears to contribute to poor risk factor control.

No differences in psychosocial factors (i.e. anxiety, depression, worry, type D personality illness perception) were found in patients with prediabetes or with T2D in the present study, apart from the higher prevalence of insomnia among T2D compared with prediabetic patients. Psychosocial factors like diabetes distress, depression, and anxiety are prevalent in general populations with diabetes [34], and associated with increased risk of developing T2D in subjects with prediabetes [35]. The present selection of CHD patients may in part account for differences when compared with studies of diabetic populations. Furthermore, the level of psychosocial distress may decrease with increasing time since $\mathrm{CHD}$ events [36] and the association between psychosocial factors and glycaemic status may potentially be different if these factors had been assessed at the time of the index event. According to a recent study [12], depression and other psychosocial factors were not associated with the $\mathrm{HbA}_{1 \mathrm{c}}$ level in patients with T2D. Diabetes distress has recently been suggested to be more important for glycaemic control in patients with diabetes than clinical depression or depressive symptoms [13, 37].

The prevalence of insomnia accords to previous reports from the general population [38] and T2D patients [39]. A significant relationship between sleep problems and increased $\mathrm{HbA}_{1 \mathrm{c}}$ has been found in most, but not all, studies [40]. Patients with T2D and sleep problems have been considered a high-risk group for disease progression and 
might have resistance to standard treatment for T2D [40]. The pathways linking insomnia and glycaemic control remain unknown and are not determined in our study applying a cross-sectional design. The high prevalence of insomnia in T2D in the present study favours the previous recommendation that screening for sleep disturbance should be part of the management of T2D [41]. Sleep disorders are in general likely to be under-recognized and under-reported in the health care system [38]. Effective interventions to improve insomnia (pharmacotherapy and cognitive behaviour therapy) are available [40]. Interestingly, few studies have addressed the relationship between sleep and prediabetes. We did not find a significant association between insomnia and prediabetes, as reported by two previous studies excluding patients with CVD [42, 43]. Selection bias and differences in assessment methods may explain the differences. Separate insomnia symptoms (e.g. sleep onset, maintenance, early awakening, feeling adequately rested) were not explored separately in the present study. Which insomnia/sleep symptoms may have the strongest associations with prediabetes and T2D should be explored in future studies.

Immigrants from Asia and Africa living in Europe have a higher prevalence of T2D and are diagnosed earlier in life compared to native Europeans [44, 45]. In line with this, our coronary population had a three times higher prevalence of first and second generation ethnic minorities among patients with T2D compared to those with normoglycemia or prediabetes. Similar to several earlier studies [19], our study also found ethnic minorities with T2D to have inferior glycaemic control. Ethnic disparities in sociodemographic, cultural, and psychosocial factors may contribute to the observed ethnic inequalities in diabetes management [46]. In this respect, the high frequency of clinically significant symptoms of anxiety (29\%), depression (24\%), and insomnia (75\%) observed in the subgroup with ethnic minority background, is a potentially important observation in the present study. Although these results must be interpreted with care due to the small numbers, the findings call for further studies to explore the role of psychosocial factors in ethnic minorities. Furthermore, these findings may encourage clinicians to recognize psychosocial distress as a potential barrier to secondary prevention in cardiovascular disease and in the management of T2D.

The proportion of patients with known T2D at the time of the index event (16\%) was lower than reported in the latest EuroAspire survey (33\%) [47], with comparable inclusion criteria including age distribution, and prevalence of obesity. Patient inclusion from largely academic centres [47] with potentially more focus on coronary prevention as well as more systematically screening for T2D than in everyday clinical practice, may, in part, account for the difference. At follow-up, an additional $6 \%$ of our patients fulfilled the diagnostic criteria for $\mathrm{T} 2 \mathrm{D}$, whereas the prevalence of undetected T2D in EuroAspire was 19\%. Differences in prevalence rates may be explained by differences in measurements, as the latter study also screened the patients by an oral glucose tolerance test [47]. Systematic screening with both $\mathrm{HbA}_{1 \mathrm{c}}$ and oral glucose tolerance test has recently been proven to identify more individuals with T2D than each of them alone [48]. Thus, more patients with T2D would potentially have been diagnosed in the present study if screened by both tests. This highlights the need for better integration of systematic screening strategies for T2D after hospitalization for coronary events.

\section{Study limitations and strengths}

Most study factors in the present study were measured at one point in time and are thus prone to measurement and recall bias. However, a reproducibility study of the NOR-COR questionnaire demonstrated highly acceptable test-retest values for all key items and instruments [16]. The sample size does not allow sub-group analyses (e.g. age and gender) in the subgroup with T2D. The validity of using a single HbA1c measurement for the diagnosis of diabetes is suboptimal, as WHO guidelines advocate at least one additional HbA1c or plasma glucose test result with a value in the diabetic range in order to confirm the diagnosis; either fasting, from a random (casual) sample, or from the oral glucose tolerance test (OGTT) [49]. For the index hospitalization, however, diabetic status was based upon treatment with antidiabetic drugs or a T2D diagnosis recovered from hospital records at the time of the index event. Since diabetes diagnostics were not performed routinely at the time of the index event, the proportion of patients receiving their first T2D diagnosis during the index hospitalization remains unknown. Due to this limitation of the diagnostic test, some asymptomatic patients with diabetes may have been missed at follow-up. Our diagnostic criteria are, however, in accordance with the most recent US guidelines [7] and those of the WHO [49]. Furthermore, reporting bias of the T2D diagnosis in the hospital medical records might have occurred. Accordingly, some of the patients classified as new-onset T2D based $\mathrm{HbA}_{1 \mathrm{c}}$ at follow-up may have also had known T2D at the time of the index event. Our study design did not incorporate echocardiographic measurements in order to detect possible deterioration in left ventricular function in patients with ST-elevation myocardial infarction who had conventional glycaemic control. Although this study provides a comprehensive evaluation of determinants associated with prediabetes and T2D, additional confounders should be considered, including family history of diabetes, the duration of T2D and details on T2D management in general practice. Moreover, information about the different oral antidiabetic drugs prescribed 
at the time of the index coronary event and the reasons for admission to or non-participation with cardiac rehabilitation were not available. We did not assess sleep duration and objective measures of sleep and did not control for use of hypnotics, sedative, use of caffeine and obstructive sleep apnoea syndrome. The retrospective design with follow up times of 2-36 months after the index coronary event gives some indication of how $\mathrm{HbA}_{1 \mathrm{c}}$ and the study factors vary by time. A prospective design with repeated measurements is required to explore the influence of time properly. The representative cohort from routine clinical practice, the high participation rate (i.e. $83 \%$ ) and the comprehensive data set are important strengths of the study.

\section{Conclusion}

Prediabetes and T2D are prevalent conditions both prior and subsequent to coronary events. Along with obesity and hypertension, insomnia and low drug adherence were the major modifiable factors associated with T2D, whereas smoking and non-participation in cardiac rehabilitation were the factors associated with prediabetes. Further research on the effect of individual tailoring, addressing the reported significant predictors of failure, is needed to improve glycaemic control.

\section{Abbreviations}

CHD: Coronary heart disease; CRP: C-reactive protein; $\mathrm{HbA}_{1}$ : Glycated haemoglobin; HDL-C: High-density lipoprotein-cholesterol; LDL-C: lowdensity lipoprotein-cholesterol; T2D: Type 2 diabetes

\section{Acknowledgements}

The NOR-COR project originates from the Department of Medicine, Drammen Hospital Trust, with the study carried out at both Drammen and Vestfold Hospitals. The project developed through collaboration with research communities at the University of Oslo. The authors thank the study patients for participating and the study personnel for their invaluable contribution. The authors also thank Matthew McGee at the Center for Morbid Obesity at Vestfold Hospital for proofreading the manuscript.

\section{Funding}

The study was funded by grants from the Department of Medicine, Drammen Hospital Trust (grant number 1703001 project 9603003) and the Department for Cardiology, Vestfold Hospital Trust (grant number 703110 project 19440). Munkhaugen receives funding from the National Association for Public Health ("Nasjonalforeningen for Folkehelsen").

\section{Availability of data and materials}

According to Norwegian legislation, the Norwegian Data Protection Authority and the Committee of Ethics, we are not allowed to share original study data publicly. However, except for anthropometric data, the other essential data upon which the conclusions in the article are based will be provided by the corresponding author upon reasonable request.

\section{Authors' contributions}

$T D, J E O, J P, L G, E G, E H$ and JM contributed to the design of the study. JM, TM and $\mathrm{RH}$ contributed to the analysis, while all authors (TD, JEO, JP, LG, EG, $E H, J H, R H, S T S, T M, J M)$ contributed to the interpretation of data. JM drafted the manuscript and EH, TD, STS, and JH contributed significantly to the preparation. All the authors critically revised the manuscript and gave final approval, and agree to be accountable for all aspects of the work, ensuring both its integrity and accuracy.

\section{Ethics approval and consent to participate}

The study was approved by the Regional Committee for Medical and Health Research Ethics of the South East Region A in Norway (reference number 2013/1885) on the 12th of February, 2014 and is in accordance with the ethical principles for medical research involving human subjects outlined in the Helsinki Declaration. Written informed consent was obtained from all patients prior to study participation.

\section{Consent for publication}

Not applicable

\section{Competing interests}

The authors declare that they have no competing interests.

\section{Publisher's Note}

Springer Nature remains neutral with regard to jurisdictional claims in published maps and institutional affiliations.

\section{Author details}

'Department of Medicine, Drammen Hospital, Vestre Viken Health Trust, Dronninggata 41, 3004 Drammen, Norway. ${ }^{2}$ Morbid Obesity Centre, Vestfold Hospital Trust, Tønsberg, Norway. ${ }^{3}$ Department of Endocrinology, Morbid Obesity and Preventive Medicine, Institute of Clinical Medicine, University of Oslo, Oslo, Norway. ${ }^{4}$ Department of Medicine, Vestfold Hospital Trust, Tønsberg, Norway. ${ }^{5}$ Centre for Clinical Heart Research, Department of Cardiology, Oslo University Hospital Ullevål, Oslo, Norway. ${ }^{6}$ Faculty of Medicine, University of Oslo, Oslo, Norway. ${ }^{7}$ Department of Medicine, Drammen Hospital Trust, Drammen, Norway. ${ }^{8}$ Department of Cardiology, Oslo University Hospital Rikshospitalet, Oslo, Norway. ${ }^{9}$ Linneus University, Kalmar, Sweden. ${ }^{10}$ Department of Behavioural Sciences in Medicine and Faculty of Medicine, University of Oslo, Oslo, Norway.

Received: 18 March 2018 Accepted: 24 July 2018

Published online: 03 August 2018

References

1. Gregg EW, Cheng YJ, Narayan KM, Thompson TJ, Williamson DF. The relative contributions of different levels of overweight and obesity to the increased prevalence of diabetes in the United States: 1976-2004. Prev Med. 2007; 45:348-52.

2. Donahoe SM, Stewart GC, MCCabe CH, Mohanavelu S, Murphy SA, Cannon $\mathrm{CP}$, Antman EM. Diabetes and mortality following acute coronary syndromes. JAMA. 2007;298:765-75.

3. Sabanayagam C, Liew G, Tai ES, Shankar A, Lim SC, Subramaniam T, Wong TY. Relationship between glycated haemoglobin and microvascular complications: is there a natural cut-off point for the diagnosis of diabetes? Diabetologia. 2009;52:1279-89.

4. Singer DE, Nathan DM, Anderson KM, Wilson PW, Evans JC. Association of $\mathrm{HbA1C}$ with prevalent cardiovascular disease in the original cohort of the Framingham heart study. Diabetes. 1992;41:202-8.

5. Hayward RA, Reaven PD, Wiitala WL, Bahn GD, Reda DJ, Ge L, McCarren M, Duckworth WC, Emanuele NV, Investigators V. Follow-up of glycemic control and cardiovascular outcomes in type 2 diabetes. N Engl J Med. 2015;372:2197-206.

6. Fox CS, Golden SH, Anderson C, Bray GA, Burke LE, de Boer IH, Deedwania $P$, Eckel $\mathrm{RH}$, Ershow AG, Fradkin J, et al. Update on prevention of cardiovascular disease in adults with type 2 diabetes mellitus in light of recent evidence. Diabetes Care. 2015;38:1777-803.

7. American Diabetes Association. Classification and Diagnosis of Diabetes. Diabetes Care. 2017:40:511-s24

8. American Diabetes Association. Standards of medical care in diabetes-2011. Diabetes Care. 2011;34 Suppl 1:S11-S61

9. Huang Y, Cai X, Mai W, Li M, Hu Y. Association between prediabetes and risk of cardiovascular disease and all cause mortality: systematic review and meta-analysis. BMJ. 2016;355:i5953.

10. Gillies CL, Abrams KR, Lambert PC, Cooper NJ, Sutton AJ, Hsu RT, Khunti K. Pharmacological and lifestyle interventions to prevent or delay type 2 diabetes in people with impaired glucose tolerance: systematic review and meta-analysis. BMJ. 2007;334:299.

11. Aikens JE. Prospective associations between emotional distress and poor outcomes in type 2 diabetes. Diabetes Care. 2012;35:2472-8. 
12. Aghili R, Polonsky WH, Valojerdi AE, Malek M, Keshtkar AA, Esteghamati A, Heyman M, Khamseh ME. Type 2 diabetes: model of factors associated with glycemic control. Can J Diabetes. 2016;40:424-30.

13. Fisher L, Mullan JT, Arean P, Glasgow RE, Hessler D, Masharani U. Diabetes distress but not clinical depression or depressive symptoms is associated with glycemic control in both cross-sectional and longitudinal analyses. Diabetes Care. 2010;33:23-8.

14. Munkhaugen J, Sverre E, Peersen K, Gjertsen E, Gullestad L, Moum T, Otterstad JE, Perk J, Husebye E, Dammen T. The role of medical and psychosocial factors for unfavourable coronary risk factor control. Scand Cardiovasc J. 2015;50:1-32.

15. Statistics Norway. https://www.ssb.no/befolkning/statistikker/flytting (Accessed 25 Apr 2017) and http://cvdnor.b.uib.no/files/2013/08/ CVDNOR-Data-and-Quality-Report1.pdf (Date of origination: July, 2013. Accessed 25 May 2016).

16. Peersen K, Munkhaugen J, Gullestad L, Dammen T, Moum T, Otterstad JE. Reproducibility of an extensive self-report questionnaire used in secondary coronary prevention. Scand J Public Health. 2017;45:269-76.

17. Kurtze N, Rangul V, Hustvedt BE, Flanders WD. Reliability and validity of selfreported physical activity in the Nord-Trøndelag health study: HUNT 1. Scand J Public Health. 2008:36:52-61.

18. Okwechime IO, Roberson S, Odoi A. Prevalence and predictors of prediabetes and diabetes among adults 18 years or older in Florida: a multinomial logistic modeling approach. PLoS One. 2015;10:e0145781.

19. Kirk JK, Bell RA, Bertoni AG, Arcury TA, Quandt SA, Goff DC Jr, Narayan KM. Ethnic disparities: control of glycemia, blood pressure, and LDL cholesterol among US adults with type 2 diabetes. Ann Pharmacother. 2005;39:1489-501.

20. Ibanez B, James S, Agewall S, Antunes MJ, Bucciarelli-Ducci C, Bueno H, Caforio ALP, Crea F, Goudevenos JA, Halvorsen S, et al. 2017 ESC guidelines for the management of acute myocardial infarction in patients presenting with ST-segment elevation. Eur Heart J. 2018;39:119-77.

21. Anderson JL, Adams CD, Antman EM, Bridges CR, Califf RM, Casey DE Jr, Chavey WE 2nd, Fesmire FM, Hochman JS, Levin TN, et al. 2012 ACCF/AHA focused update incorporated into the ACCF/AHA 2007 guidelines for the management of patients with unstable angina/non-ST-elevation myocardial infarction. J Am Coll Cardiol. 2013:61:e179-347.

22. Marfella R, Rizzo MR, Siniscalchi M, Paolisso P, Barbieri M, Sardu C, Savinelli A, Angelico N, Del Gaudio S, Esposito N, et al. Peri-procedural tight glycemic control during early percutaneous coronary intervention up-regulates endothelial progenitor cell level and differentiation during acute STelevation myocardial infarction: effects on myocardial salvage. Int J Cardiol. 2013;168:3954-62.

23. Lenzen M, Ryden L, Ohrvik J, Bartnik M, Malmberg K, Scholte Op Reimer W, Simoons ML. Diabetes known or newly detected, but not impaired glucose regulation, has a negative influence on 1-year outcome in patients with coronary artery disease. Eur Heart J. 2006; 27:2969-74.

24. Norhammar A, Malmberg K, Diderholm E, Lagerqvist B, Lindahl B, Ryden L, Wallentin L. Diabetes mellitus: the major risk factor in unstable coronary artery disease even after consideration of the extent of coronary artery disease and benefits of revascularization. J Am Coll Cardiol. 2004:43:585-91.

25. Grundy SM, Cleeman JI, Daniels SR, Donato KA, Eckel RH, Franklin BA, Gordon DJ, Krauss RM, Savage PJ, Smith SC Jr, et al. Diagnosis and management of the metabolic syndrome: an American Heart Association/ National Heart, Lung, and Blood Institute scientific statement. Circulation. 2005:112:2735-52.

26. Creager MA, Luscher TF, Cosentino F, Beckman JA. Diabetes and vascular disease: pathophysiology, clinical consequences, and medical therapy: part I. Circulation. 2003;108:1527-32.

27. Balestrieri ML, Rizzo MR, Barbieri M, Paolisso P, D'Onofrio N, Giovane A, Siniscalchi M, Minicucci F, Sardu C, D'Andrea D, et al. Sirtuin 6 expression and inflammatory activity in diabetic atherosclerotic plaques: effects of incretin treatment. Diabetes. 2015;64:1395-406.

28. lannaccone M, Quadri G, Taha S, D'Ascenzo F, Montefusco A, Omede' P, Jang IK, Niccoli G, Souteyrand G, Yundai C, et al. Prevalence and predictors of culprit plaque rupture at OCT in patients with coronary artery disease: a meta-analysis. Eur Heart J Cardiovasc Imaging. 2016;17:1128-37.

29. Marfella R, Ferraraccio F, Rizzo MR, Portoghese M, Barbieri M, Basilio C, Nersita R, Siniscalchi LI, Sasso FC, Ambrosino I, et al. Innate immune activity in plaque of patients with untreated and L-thyroxine-treated subclinical hypothyroidism. J Clin Endocrinol Metab. 2011;96:1015-20.
30. Marfella R, Sardu C, Calabrò P, Siniscalchi M, Minicucci F, Signoriello G, Balestrieri ML, Mauro C, Rizzo MR, Paolisso G, et al. Non-ST-elevation myocardial infarction outcomes in patients with type 2 diabetes with nonobstructive coronary artery stenosis: effects of incretin treatment. Diabetes Obes Metab. 2018;20:723-9.

31. Gaede $\mathrm{P}$, Lund-Andersen $\mathrm{H}$, Parving $\mathrm{HH}$, Pedersen $\mathrm{O}$. Effect of a multifactorial intervention on mortality in type 2 diabetes. $\mathrm{N}$ Engl J Med. 2008;358:580-91.

32. Ofori SN, Kotseva K. Comparison of treatment outcomes in patients with and without diabetes mellitus attending a multidisciplinary cardiovascular prevention programme (a retrospective analysis of the EUROACTION trial). BMC Cardiovasc Disord. 2015;15:11-7.

33. Peersen K, Munkhaugen J, Gullestad L, Liodden T, Moum T, Dammen T, Perk J, Otterstad JE. The role of cardiac rehabilitation in secondary prevention after coronary events. Eur J Prev Cardiol. 2017;24:1360-8.

34. Roy T, Lloyd CE. Epidemiology of depression and diabetes: a systematic review. J Affect Disord 2012;142 Suppl:S8-21.

35. Deschenes SS, Burns RJ, Graham E, Schmitz N. Prediabetes, depressive and anxiety symptoms, and risk of type 2 diabetes. A community-based cohort study. J Psychosom Res. 2016;89:85-90.

36. Murphy BM, Elliott PC, Higgins RO, Le Grande MR, Worcester MU, Goble AJ, Tatoulis J. Anxiety and depression after coronary artery bypass graft surgery: most get better, some get worse. Eur J Cardiovasc Prev Rehabil. 2008;15:434-40.

37. Wong EM, Afshar R, Qian H, Zhang M, Elliott TG, Tang TS. Diabetes distress, depression and glycemic control in a Canadian-based specialty care setting. Can J Diabetes. 2017:41:362-5.

38. Morin CM, LeBlanc M, Daley M, Gregoire JP, Merette C. Epidemiology of insomnia: prevalence, self-help treatments, consultations, and determinants of help-seeking behaviors. Sleep Med. 2006;7:123-30.

39. Zhu B, Hershberger PE, Kapella MC, Fritschi C. The relationship between sleep disturbance and glycaemic control in adults with type 2 diabetes: an integrative review. J Clin Nurs. 2017;26:4053-64.

40. Tan X, van Egmond L, Chapman CD, Cedernaes J, Benedict C. Aiding sleep in type 2 diabetes: therapeutic considerations. Lancet Diabetes Endocrinol. 2017;6:60-8

41. Khan MS, Aouad R. The effects of insomnia and sleep loss on cardiovascular disease. Sleep Med Clin. 2017;12:167-77.

42. Engeda J, Mezuk B, Ratliff S, Ning Y. Association between duration and quality of sleep and the risk of pre-diabetes: evidence from NHANES. Diabet Med. 2013:30:676-80.

43. Kowall B, Lehnich AT, Strucksberg KH, Fuhrer D, Erbel R, Jankovic N, Moebus $\mathrm{S}$, Jockel $\mathrm{KH}$, Stang A. Associations among sleep disturbances, nocturnal sleep duration, daytime napping, and incident prediabetes and type 2 diabetes: the Heinz Nixdorf recall study. Sleep Med. 2016;21:35-41.

44. Wandell PE, Carlsson A, Steiner KH. Prevalence of diabetes among immigrants in the Nordic countries. Curr Diabetes Rev. 2010;6:126-33.

45. Kumar BN, Selmer R, Lindman AS, Tverdal A, Falster K, Meyer HE. Ethnic differences in SCORE cardiovascular risk in Oslo, Norway. Eur J Cardiovasc Prev Rehabil. 2009;16:229-34.

46. Wilkinson $E$, Waqar M, Sinclair A, Randhawa G. Meeting the challenge of diabetes in ageing and diverse populations: a review of the literature from the UK. J Diabetes Res. 2016;2016:8030627. Epub 2016 Oct 17

47. Kotseva K, Wood D, De Bacquer D, De Backer G, Ryden L, Jennings C, Gyberg V, Amouyel P, Bruthans J, Castro Conde A, et al. EUROASPIRE IV: a European Society of Cardiology survey on the lifestyle, risk factor and therapeutic management of coronary patients from 24 European countries. Eur J Prev Cardiol. 2016;23:636-48.

48. Gyberg V, De Bacquer D, De Backer G, Jennings C, Kotseva K, Mellbin L, Schnell O, Tuomilehto J, Wood D, Ryden L, et al. Patients with coronary artery disease and diabetes need improved management: a report from the EUROASPIRE IV survey. Cardiovasc Diabetol. 2015;14:133.

49. WHO Guidelines Approved by the Guidelines Review Committee. Use of Glycated Haemoglobin ( $\mathrm{HbA1c}$ ) in the Diagnosis of Diabetes Mellitus: Abbreviated Report of a WHO Consultation. Geneva: World Health Organization; 2011. 